\title{
Development of High Water Selective Sodium Alginate-Silica Hybrid Membranes via Sol-gel Technique for Pervaporation Dehydration of Ethanol
}

\author{
Shang Han, Shasha $\mathrm{Na}$, Weixing $\mathrm{Li}^{*}$ and Weihong Xing
}

College of Chemistry and Chemical Engineering, Nanjing Tech University, Nanjing 210009, China

\begin{abstract}
In order to improve the performance of sodium alginate (SA) membrane for dehydration of ethanol, a new method for preparing SA-silica membranes using sol-gel was proposed. The hybrid pervaporation membranes were prepared by hydrolysis and condensation of tetraethyl orthosilicate (TEOS) within SA aqueous solution. The obtained membranes were characterized by scanning electron microscope (SEM), energy-dispersive X-ray spectroscopy (EDX), Fourier Transform Infrared Spectroscopy (FTIR), X-ray diffraction (XRD), Atomic Force Microscope (AFM), thermogravimetry (TG) and differential scanning calorimetry (DSC). Then the membranes were tested by pervaporation dehydration of ethanol. FTIR indicated that -Si-O-C bonds were obtained. XRD showed the $\mathrm{SiO}_{2}$ particles were generated in the SA matrix. The thermal stability of hybrid membranes was enhanced after incorporating TEOS into SA from the DSC results. The tensile strength of SA-40 membrane was improved after incorporating TEOS into SA. The effect of mass ratio of TEOS to SA on the separation performance was investigated. The permeate flux was improved with increasing mass ratio of TEOS to SA. And the result showed that the permeate flux reached $274 \mathrm{~g} \mathrm{~m}^{-2} . \mathrm{h}^{-1}$ with a high separation factor 17990 when the amount of water in feed was $10 \mathrm{wt} \%$ at $50^{\circ} \mathrm{C}$. The Arrhenius apparent activation energy for permeation has been estimated from the temperature dependence of permeation values. The activation energy for permeation was $15.1 \mathrm{~kJ} / \mathrm{mol}$.
\end{abstract}

Keywords: Sodium alginate; Tetraethyl orthosilicate; Pervaporation; Ethanol; Dehydration

\section{Introduction}

Pervaporation (PV) has attracted growing interests in the separation process because of its energy-saving characteristics and high separation performance compared to traditional techniques [1,2]. It's widely used in dehydration of ethanol, methanol and isopropanol. Sodium alginate (SA), a kind of polysaccharides extracted from seaweed, is considered as a prospective dehydration membrane material for its intrinsic properties such as good hydrophilicity, outstanding water solubility and good film-formation characteristics $[3,4]$. The development of SA membrane has been focused on for the decades. The performance of pure SA membrane is not so good to dehydrate organics. In order to improve the separation performance of SA membrane, modification methods such as blending, cross-linking and adding fillers have been applied. Dong et al. [5] blended SA with poly-(vinyl alcohol) (PVA) for separating ethanol aqueous solutions. The prepared membranes showed better pervaporation performance for ethanol aqueous solution with a permeate flux of $384 \mathrm{~g} \mathrm{~m}^{-2} \cdot \mathrm{h}^{-1}$ and a separation factor of 384 for $90 \mathrm{wt} \%$ ethanol aqueous solution at $45^{\circ} \mathrm{C}$. Pan et al. [6] incorporated reduced grapheme oxide into SA matrix. The hybrid membranes exhibited optimum separation performance with a separation factor of 1566 and a permeate flux of $1699 \mathrm{~g} \mathrm{~m}^{-2} \cdot \mathrm{h}^{-1}$. Generally, metal oxides were added into the SA membrane for higher mechanical property and permeability. Organic-inorganic hybrid materials may be a proper candidate for having the advantages of organic moiety and inorganic moiety which have been recognized in various fields [7-9]. Inorganic particles have a good thermal stability as well as high mechanical strength. The separation performance of the membranes can be improved by incorporating inorganic particles into PV membranes [10-15]. Blending inorganic particles into polymer matrix is a simple way to prepare organic-inorganic hybrid membranes.

However, the inorganic particles often behave serious aggregation. In order to improve the dispersion performance of inorganic particles in casting membrane solution, in situ generation of inorganic particles via sol-gel method in polymer matrix is focused on. The generated inorganic particles can be dispersed in the organic membranes homogeneously. Kariduraganavar et al. [16] prepared chitosan based hybrid membranes by incorporating 2-(3, 4-epoxycyclohexyl) ethyltrimethoxysilane into chitosan matrix using a sol-gel technique. And the developed hybrid membranes could be effectively used to break the azeotropic point of water-isopropanol mixtures with separation selectivity of 17990 and a flux of $29.2 \mathrm{~g} \mathrm{~m}^{-2} \cdot \mathrm{h}^{-1}$ at $30^{\circ} \mathrm{C}$ for $10 \mathrm{mass} \%$ of water. Jiang et al. [17] incorporated TiCl4 into CS membrane, the membrane exhibited the optimal pervaporation performance with a permeate flux of $1403 \mathrm{~g} \mathrm{~m}^{-2} \cdot \mathrm{h}^{-1}$ and a separation factor of 730 for $90 \mathrm{wt} \%$ ethanol aqueous solution at $77^{\circ} \mathrm{C}$. The sol-gel reaction is helpful to the hybridization of organic and inorganic components which can form covalent bonds and hydrogen bonds between the polymeric phase and inorganic phase [18-20]. Clearly, it is efficient to hybridize the organic and inorganic components homogeneously.

The aim of this work is to attempt preparation of a SA-silica hybrid membrane with high water selectivity via sol-gel technique for dehydration of ethanol. The proposed preparation method of the hybrid SA-silica membrane via sol-gel was rarely reported, and the

*Corresponding author: Weixing $\mathrm{Li}$, College of Chemistry and Chemical Engineering, Nanjing Tech University, Nanjing 210009, China, Tel: +86-2583172286; Fax: +86-25-83172292; E-mail: wxli@njtech.edu.cn

Received September 24, 2016; Accepted November 08, 2016; Published November 16, 2016

Citation: Han S, Na S, Li W, Xing W (2016) Development of High Water Selective Sodium Alginate-Silica Hybrid Membranes via Sol-gel Technique for Pervaporation Dehydration of Ethanol. J Membra Sci Technol 6: 165. doi:10.4172/21559589.1000165

Copyright: (c) 2016 Han S, et al. This is an open-access article distributed under the terms of the Creative Commons Attribution License, which permits unrestricted use, distribution, and reproduction in any medium, provided the original author and source are credited. 
Citation: Han S, Na S, Li W, Xing W (2016) Development of High Water Selective Sodium Alginate-Silica Hybrid Membranes via Sol-gel Technique for Pervaporation Dehydration of Ethanol. J Membra Sci Technol 6: 165. doi:10.4172/2155-9589.1000165

Page 2 of 7

latest report about hybrid membranes prepared by incorporating silica precursors into alginate matrix was study by Choudhari [21]. Here, we try to investigate the membrane preparation parameters and characterization of the separation characteristics for PV of ethanol solution.

\section{Experimental}

\section{Materials}

Sodium alginate, tetraethyl orthosilicate, ethanol (99.7\%), glutaraldehyde solution (25\%) and sulfuric acid were supplied by Sinopharm Chemical Reagent Co., Ltd. Deionized water was produced by a Milli-Q system (Millipore, US).

\section{Membrane fabrication}

The $3 \mathrm{wt} \%$ SA solution was prepared by dissolving SA in deionized water with stirring for $3 \mathrm{~h}$ at $60^{\circ} \mathrm{C}$. Then a known amount of TEOS was added to the SA solution. Subsequently, quantitative of glutaraldehyde and sulfuric acid were added into the mixtures which were used as cross-linking agent and catalyst, respectively. Then the solution was stirred for $24 \mathrm{~h}$. After that the solution was cast onto an organic glass plate with the aid of automatic film blowing machine. Dried membranes were peeled off from the glass plate. The mass ratio of TEOS to SA was varied as $0,10,20,30,40$ and $60 \%$, and the resulting hybrid membranes were designated as SA, SA-10, SA-20, SA-30, SA-40 and SA-60.

\section{Membrane characterization}

The interaction properties among different chemical groups of the hybrid membranes were characterized by Fourier Transform Infrared Spectroscopy (FTIR) spectrometer (AVATAR360, Thermo Nicolet, USA). The morphologies of membranes were conducted with a fieldemission scanning electron microscopy (FESEM) (S-4800, Hitachi, Japan). The silicon element was recorded by energy-dispersive $\mathrm{X}$-ray spectroscopy (EDX) equipped on (FESEM). The crystalline structure of membrane was investigated using an X-ray diffraction (XRD) (Miniflex 600, Rigaku, Japan) in the range of $6-80^{\circ}$ at the scan rate of $15^{\circ} \mathrm{min}^{-1}$. Tensile strength of the SA, SA-10, SA-20, SA-30, SA-40 and SA-60 matrix membranes were measured using the universal testing machine (CMT-6203, MTS SANS, China). Thermogravimetric (TG) and differential scanning calorimetry (DSC) analysis were conducted by a thermoanalyzer (Sta 449 F3, Netzsch, Germany) at a heating rate of $10^{\circ} \mathrm{C} / \mathrm{min}$ under nitrogen atmosphere to analysis the thermal stability of all membranes. The membrane thickness was determined by a field-emission scanning electron microscopy (FESEM) (S-4800, Hitachi, Japan). The increase in surface area and surface roughness was calculated by Atomic Force Microscope (AFM) (XE100, Park systems, Korea).

\section{Swelling experiments}

The dry membrane was weighed as $\mathrm{W}_{\mathrm{d}}$, and then it was immersed into $10 \mathrm{wt} \%$ water-ethanol solutions for $24 \mathrm{~h}$ at room temperature to achieve equilibrium. The swollen membranes were taken out carefully and the solution on the membranes surface was wiped off by tissue paper, and then weighed as quickly as possible. The mass of the swollen membranes was measured as Ws (supplementary Table 1). The degree of swelling (DS) was calculated by the following Eq. (1).

$$
D S(\%)=\frac{W_{s}-W_{d}}{W_{d}} \times 100
$$

Where $\mathrm{W}_{\mathrm{d}}$ and $\mathrm{W}_{\mathrm{s}}$ are the mass of the dry and swollen membranes, respectively.

\section{Pervaporation experiments}

PV experiments were carried out using an indigenously designed apparatus. The feed temperature was controlled by constant temperature oil bath. The effective membrane area was $0.0011 \mathrm{~m}^{2}$. The permeated solution was condensed downstream by liquid nitrogen. A vacuum pump in the downstream maintained the pressure at about $300 \mathrm{~Pa}$. The permeate flux was defined by Eq. (2).

$$
J=\frac{W}{A \times t}
$$

Where $\mathrm{W}$ represents the mass of permeate over a certain time interval $t, A$ represents the effective membrane area.

The compositions of feed and permeate were determined by gas chromatograph (GC-2014, Shimadu, Japan) which was equipped with a thermal conductivity detector (TCD). The length of PORAPAK ${ }^{\circ} \mathrm{Q}$ (mesh 50-80) column was $2 \mathrm{~m}$. Helium (99.9999\%) was used as the carrier gas. Both the injector and detector temperatures were $200^{\circ} \mathrm{C}$ and the column temperature was $180^{\circ} \mathrm{C}$. The bridge current was 90 $\mathrm{mA}$. The separation factor ( $\alpha$ ) was defined by Eq. (3).

$$
\alpha=\frac{Y_{\mathrm{W}} / \mathrm{Y}_{\mathrm{E}}}{X_{W} / X_{E}}
$$

Where $\mathrm{X}_{\mathrm{W}}, \mathrm{X}_{\mathrm{E}}, \mathrm{Y}_{\mathrm{W}}$ and $\mathrm{Y}_{\mathrm{E}}$ are the weight fractions of water and alcohol in the feed and permeate, respectively.

\section{Results and Discussion}

\section{Membrane characterization}

FTIR spectra analysis: Silanol groups were obtained by hydrolyzing TEOS. The silanol groups yielded siloxane bonds due to the dehydration or dealcoholysis reaction with other silanol or SA during the membrane drying [22]. Figure 1 shows the FT-IR spectra of SA membrane and hybrid membranes. A characteristic band at around $3243 \mathrm{~cm}^{-1}$ in SA pristine membrane spectra corresponds to $-\mathrm{OH}$ stretching vibrations. The peaks at $1591 \mathrm{~cm}^{-1}$ and $1406 \mathrm{~cm}^{-1}$ correspond to asymmetric and symmetric stretching of carboxyl group of SA, respectively. Peaks appeared at around $1010-1030 \mathrm{~cm}^{-1}$ are assigned to -C-O-C stretching of SA membrane. However, the intensity of these bands for the hybrid membranes increased which suggested the formation of -Si-O-C bonds [23]. That's because -Si-O stretching also appears at the same wave numbers of -C-O stretching.

XRD analysis: The XRD patterns of SA membrane and hybrid membranes are shown in Figure 2. The SA membrane exhibited a broad peak around $13^{\circ}$ [24], which is attributed to the presence of amorphous region in the polymer. After incorporating TEOS into SA matrix, broad peaks of $\mathrm{SiO}_{2}$ at around $21^{\circ}$ appeared in hybrid membranes [25]. It's clear that the generated $\mathrm{SiO}_{2}$ particle was in an amorphous form. The intensity of the $\mathrm{SiO}_{2}$ peaks increased gradually from SA-10 to SA-60 membrane with increasing mass ratio of TEOS to SA. This is because more $\mathrm{SiO}_{2}$ particles were generated upon increasing TEOS content.

\begin{tabular}{|c|c|}
\hline Membrane & Tensile strength (MPa) \\
\hline SA & 26.8 \\
\hline SA-10 & 26.9 \\
\hline SA-20 & 16.8 \\
\hline SA-30 & 16.1 \\
\hline SA-40 & 28.8 \\
\hline SA-60 & 31.9 \\
\hline
\end{tabular}

Table 1: Mechanical strength data of SA and hybrid membranes. 


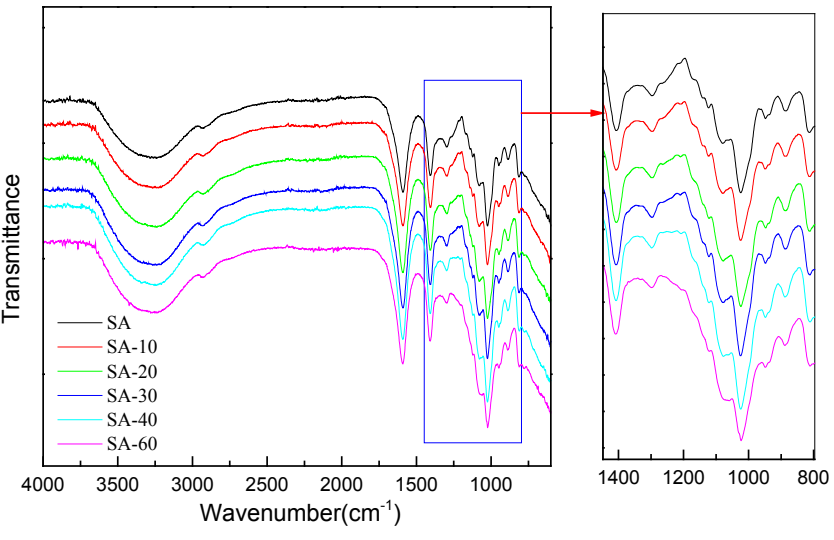

Figure 1: FT-IR spectra of SA membrane and hybrid membranes.

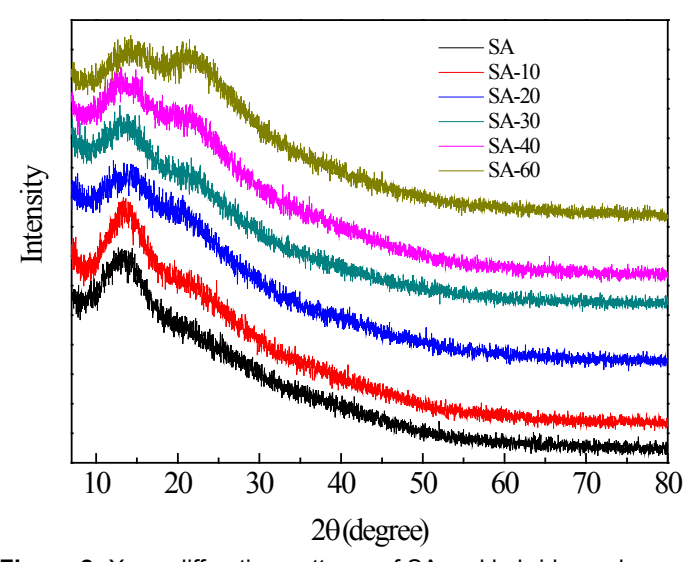

Figure 2: X-ray diffraction patterns of SA and hybrid membranes.

TG and DSC analysis: The thermal stability of the hybrid membranes was evaluated by TG and DSC under nitrogen flow. The results are shown in Figure 3. The membranes had three stages of weight loss from Figure 3a. The first weight loss of $20 \%$ occurred between ambient temperature and $200^{\circ} \mathrm{C}$ corresponds to the physically absorbed water molecules. The second thermal event occurring in the range of $200-250^{\circ} \mathrm{C}$, which is attributed to the decomposition of SA matrix and the weight loss was about $25 \%$. The third stage, for temperature higher than $250^{\circ} \mathrm{C}$, corresponds to the residual decomposition reactions. What's more, it can be clearly seen that the decomposition temperature of hybrid membranes were higher than the SA membrane in the DSC patterns (Figure 3b). It indicated that the thermal stability of membranes was virtually improved after hybridization, which is mainly due to a hindrance of chain mobility of SA by the generation of $\mathrm{SiO}_{2}$ and the hydrogen bonding between $\mathrm{SA}$ and $\mathrm{SiO}_{2}$.

SEM and EDX characterizations: Figure 4 illustrates the SEM and EDX photographs of hybrid membranes. The surface view of SA membrane was smooth. But the surface of hybrid membranes became rougher with increasing mass ratio of TEOS to SA. From the EDX pictures, it can be seen that the SA membrane had no silicon element. However, the silicon element was obtained from the hybrid membranes, suggesting that the generation of $\mathrm{SiO}_{2}$ particles. This is agreement with the XRD results, because the formation of $\mathrm{SiO}_{2}$ particles was also verified by XRD analysis. The EDX Si-mapping of the SA-40 membrane in Figure 4e-3 showed that silicon element was distributed uniformly in the SA matrix which indicated the homogeneous hybrid structure.
Tensile strength test: The maximum tensile strengths of all membranes are given in Table 1. The tensile strengths of SA, SA-10, SA-20, SA-30, SA-40 and SA-60 membrane were $26.8 \mathrm{MPa}, 26.9 \mathrm{MPa}$, 16.8 MPa, 16.1 MPa, 28.8 MPa and $31.9 \mathrm{MPa}$, respectively. These data indicated higher mechanical strengths for the hybrid membranes expect SA-20 and SA-30 membrane as compared to SA membrane. The decrease of tensile strengths of SA-20 and SA-30 membranes may be because of the uniform dispersion in SA matrix as can be observed in the SEM images. The tensile strengths of the other membranes were improved by incorporating TEOS into SA matrix. It is due to the hydrogen and covalent bonds between $\mathrm{SiO}_{2}$ and SA.

\section{Swelling behaviors}

Membrane swelling plays a key role in separation property of the membrane which depends on the membrane structure. Figure 5 shows the effect of the mass ratio of TEOS to SA on the degree of swelling for hybrid membranes in $10 \mathrm{wt} \%$ water-ethanol mixtures at $25^{\circ} \mathrm{C}$. It can be seen that the degree of swelling was enhanced with increasing mass ratio of TEOS to SA. This is attributed to increased hydrophilic nature of the hybrid membranes owing to the presence of $\mathrm{SiO}_{2}$ particles. And thereby adsorption of water and ethanol molecules increased resulting to degree of swelling.

\section{Pervaporation performance}

TG and DSC analysis: In general, the diffusion of pervaporation process plays an important role in permeate flux and the diffusion is influenced by membrane thickness. Table 2 illustrates that the permeate flux decreased with increasing membrane thickness. That's because the
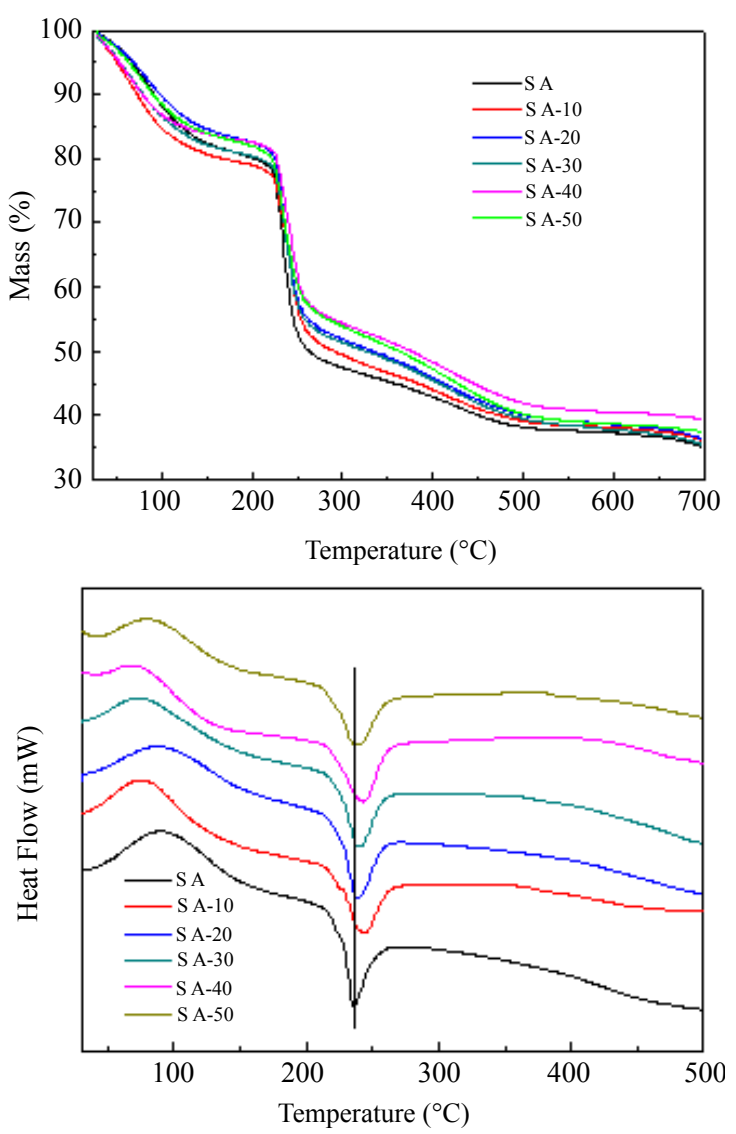

Figure 3: TG(a) and DSC(b) curves of hybrid membranes. 
Citation: Han S, Na S, Li W, Xing W (2016) Development of High Water Selective Sodium Alginate-Silica Hybrid Membranes via Sol-gel Technique for Pervaporation Dehydration of Ethanol. J Membra Sci Technol 6: 165. doi:10.4172/2155-9589.1000165
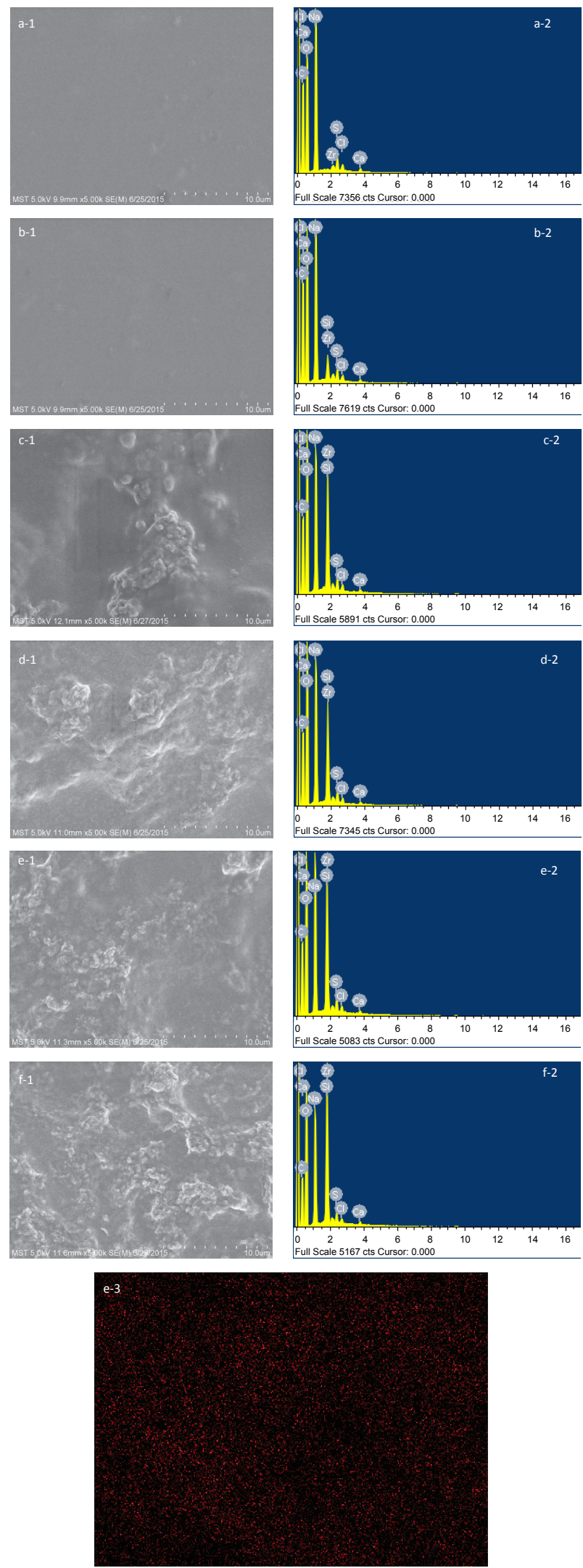

Figure 4: SEM images of hybrid membranes: surface images of SA to SA60 membranes (a-1, b-1, c-1, d-1, e-1,f-1); EDX of SA to SA-60 hybrid membranes (a-2, b-2, c-2, d-2, e-2,f-2,e-3(Si distribution)).

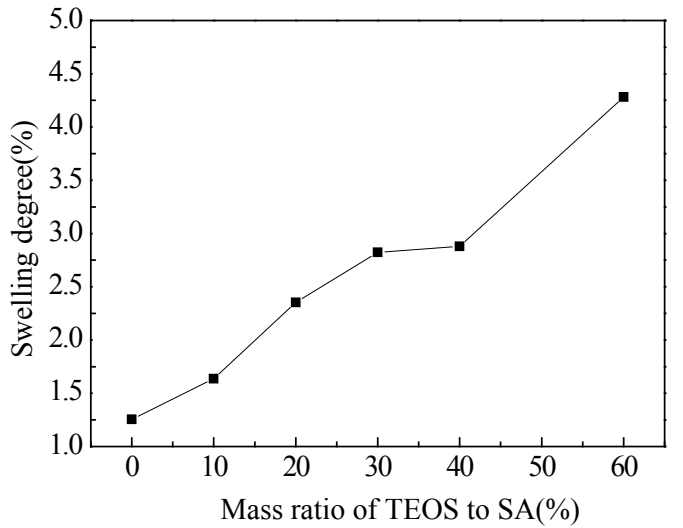

Figure 5: Effect of mass ratio of TEOS to SA on the degree of swelling of hybrid membranes $(12 \mu \mathrm{m})$.

\begin{tabular}{|c|c|c|}
\hline Membrane Thickness $(\boldsymbol{\mu m})$ & Flux $\left(\mathbf{g} \cdot \mathbf{m}^{\left.-\mathbf{2} \cdot \mathbf{h}^{-\mathbf{1}}\right)}\right.$ & $\begin{array}{c}\text { Water content in } \\
\text { permeate }\end{array}$ \\
\hline 10 & 274 & 99.95 \\
\hline 15 & 248 & 99.96 \\
\hline 20 & 169 & 99.96 \\
\hline 26 & 137 & 99.94 \\
\hline
\end{tabular}

Table 2: Influence of membrane thickness on pervaporation performance (SA-40 membrane, $10 \mathrm{wt} \%$ water in the feed, $50^{\circ} \mathrm{C}$ ).

increased mass transfer resistance led to reduced diffusion rate. The upstream side of the membrane was swollen and plasticized due to adsorbed liquid molecules and allowed unrestricted transport of feed components [26]. However, the downstream side of the membrane was dry in vacuum condition, which allowed smaller sized molecules to pass through. It's notable that the water content of permeate side was nearly $100 \mathrm{wt} \%$.

Effect of mass ratio of TEOS to SA: As shown in Figure 6, Tables 3 and 4 , the generated $\mathrm{SiO}_{2}$ particles can improve the roughness of membrane surface, and the permeability is influenced by membrane roughness. Pervaporation experiment was carried out to study the effect of mass ratio of TEOS to SA on the dehydration performance of $10 \mathrm{wt} \%$ water in the feed at $50^{\circ} \mathrm{C}$. The membrane thickness was $12 \mu \mathrm{m}$. Figure 7 demonstrates that the permeate flux increased with increasing mass ratio of TEOS to SA. The permeate flux increased from 225 to $282 \mathrm{~g} \mathrm{~m}^{-2} \cdot \mathrm{h}^{-1}$ when the mass ratio increased from $0 \%$ to $60 \%$. This is mainly due to increased interaction between water molecules and membrane. The free-volume in membrane matrix increased because of generated $\mathrm{SiO}_{2}$ particles [27]. The water content of permeate side was nearly $100 \mathrm{wt} \%$ when the mass ratio of TEOS to SA was lower than $30 \%$ and decreased slightly over $30 \%$. It may be that the interaction between water molecules and membrane matrix becomes weak because of slight agglomeration of $\mathrm{SiO}_{2}$ particles.

Effect of feed temperature: Effect of feed temperature ranging from $30^{\circ} \mathrm{C}$ to $50^{\circ} \mathrm{C}$ on the $\mathrm{PV}$ performance for water-ethanol mixtures was studied using SA- 40 membrane at $10 \mathrm{wt} \%$ water in the feed, and the results are presented in Figure 8. It's observed that the permeate flux increased with increasing feed temperature which can be explained by solution-diffusion mechanism. With the increase of temperature, the vapor pressure difference increased between the upstream and downstream side of the membranes, which resulted in the enhancement of the driving force of transport. Higher temperature leads to higher molecular diffusivity [28]. Permeation of diffusing 
Citation: Han S, Na S, Li W, Xing W (2016) Development of High Water Selective Sodium Alginate-Silica Hybrid Membranes via Sol-gel Technique for Pervaporation Dehydration of Ethanol. J Membra Sci Technol 6: 165. doi:10.4172/2155-9589.1000165

Page 5 of 7
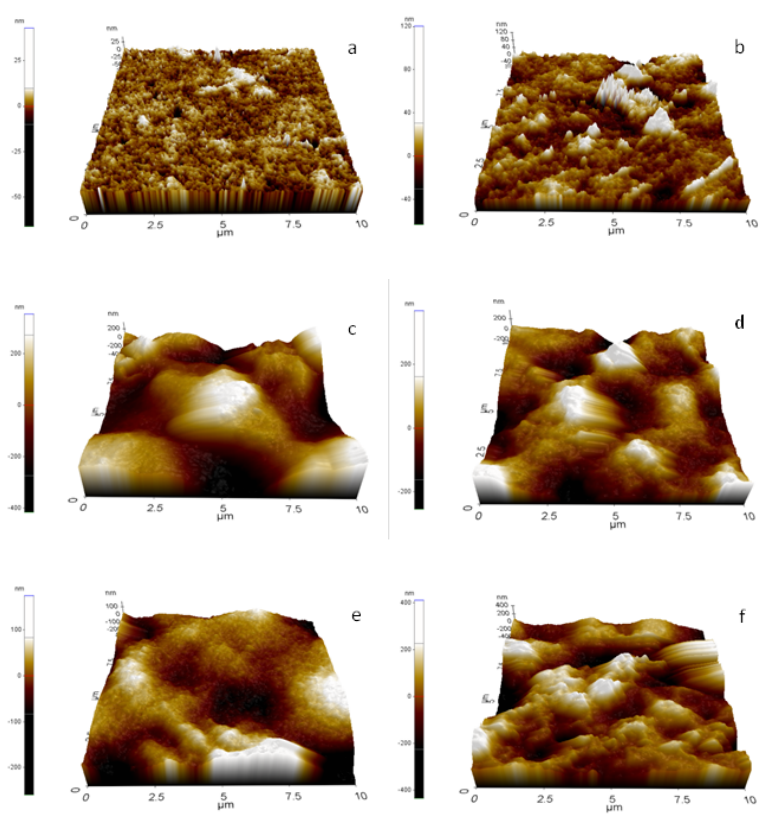

Figure 6: AFM surface images of hybrid membranes: SA(a), SA-10(b), SA20 (c), SA-30(d), SA-40(e), SA-60(f).

\begin{tabular}{|c|c|c|c|c|}
\hline Membrane & $\mathbf{T}\left({ }^{\circ} \mathbf{C}\right)$ & Flux $\left(\mathbf{g} \cdot \mathbf{m}^{-\mathbf{2}} \cdot \mathbf{h}^{-\mathbf{1}} \mathbf{)}\right.$ & Separation factor & Reference \\
\hline PVA-SA/PS & 45 & 384 & 384 & {$[5]$} \\
\hline NaAlg-zeolite beta & 50 & 166 & 465 & {$[8]$} \\
\hline NaAlg-zeolite beta & 30 & 132 & 1598 & {$[8]$} \\
\hline CS-TEOS & 80 & 284 & 460 & {$[18]$} \\
\hline NaAlg-mPTA10 & 50 & 393 & 2423 & {$[29]$} \\
\hline NaAlg-mPTA10 & 30 & 316 & 8991 & {$[29]$} \\
\hline SA- heteropolyacid & 30 & 570 & 14991 & {$[11]$} \\
\hline SA-40 & 30 & 189 & 7013 & This study \\
\hline SA-40 & 50 & 274 & 17990 & This study \\
\hline SA-60 & 50 & 282 & 4496 & This study \\
\hline
\end{tabular}

Table 3: Comparisons of pervaporation performance for dehydration of ethanol/ water mixtures with $10 \mathrm{wt} \%$ water in the feed.

\begin{tabular}{|c|c|c|}
\hline Membrane & Increase in surface area (\%) & Surface roughness(Ra) $(\mathrm{nm})$ \\
\hline SA & 0.59 & 3.63 \\
\hline SA-10 & 1.19 & 11.33 \\
\hline SA-20 & 2.88 & 112.82 \\
\hline SA-30 & 3.50 & 63.34 \\
\hline SA-40 & 0.76 & 31.68 \\
\hline SA-60 & 9.36 & 90.81 \\
\hline
\end{tabular}

Table 4: The increase in surface area and surface roughness of SA and hybrid membranes calculated by AFM.

molecules pass through the membrane becomes easier, therefore, the mass transport is faster and the total flux increases. What's more, as the temperature increased, the thermal mobility and the free volume of polymer were elevated, which led to the increase of the solubility of solution on the surface $[29,30]$. Meanwhile, the activation energy for permeation through the membrane can be described by Arrhenius relationship in Eq. (4).

$$
J=J_{0} \exp \left(\frac{-E_{P}}{R T}\right)
$$

Where $\mathrm{J}$ is the permeate flux, J0 is the pre-exponential factor, EP refers to the activation energy for permeation, $\mathrm{R}$ and $\mathrm{T}$ are the gas constant and the operating temperature, respectively. Figure 9 was the normalized Arrhenius plot. From Figure 9, the activation energy for permeation through the SA-40 membrane was calculated from the slope of the fit liner and its value was $15.1 \mathrm{~kJ} / \mathrm{mol}$ [30].

Effect of feed water composition: Feed water composition exhibits a considerable effect on membrane performance. Figure 10 shows the permeate flux against the feed water composition of ethanol/water system, and the SA-40 membrane was used. The total flux increased from 161 to $985 \mathrm{~g} \mathrm{~m}^{-2} \cdot \mathrm{h}^{-1}$ with increasing water content in the feed. This can explain that an increase of feed water concentration may lead to enhancement of membrane swelling. The surface of the membrane became more compact, which led to a positive impact on flux.

Comparisons with literature data: The present PV data compared with former results provided by other researchers are listed in Table 3 . It shows that the SA-40 membrane had higher separation factor with good permeate flux for separation of ethanol-water mixtures compared to similar data published in the literature.

\section{Conclusions}

The SA-Silica hybrid membranes were fabricated using solgel method for pervaporation dehydration of ethanol aqueous solution. The XRD characterization and SEM images indicated that $\mathrm{SiO} 2$ inorganic particles were generated by in situ hydrolysis and condensation of tetraethyl orthosilicate (TEOS) within SA aqueous

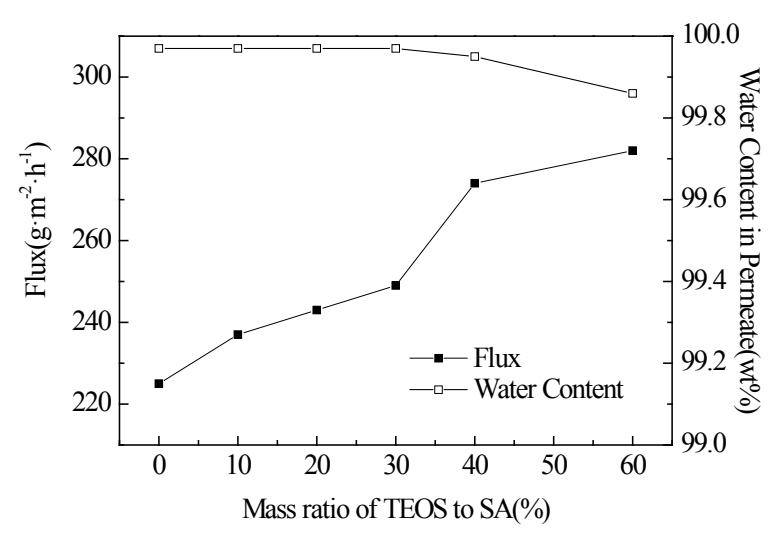

Figure 7: Effect of mass ratio of TEOS to SA on the pervaporation properties (10 wt $\%$ water in the feed, $50^{\circ} \mathrm{C}, 12 \mu \mathrm{m}$ ).

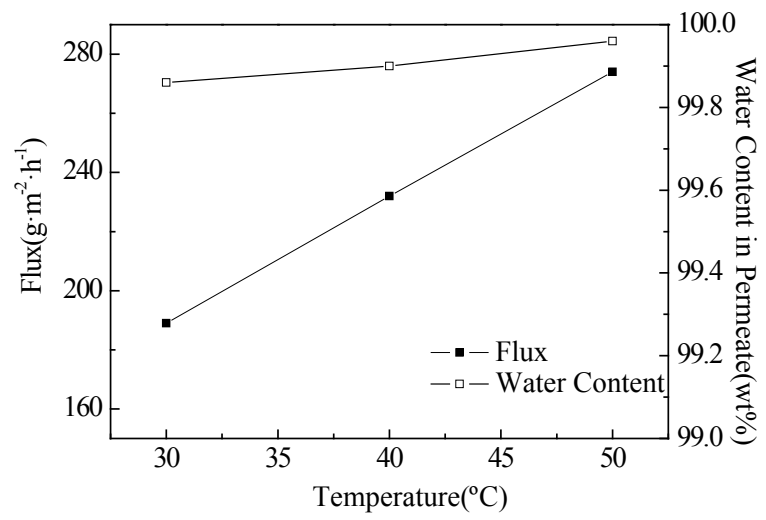

Figure 8: Effect of feed temperature on pervaporation performance (SA-40 membrane, $10 \mathrm{wt} \%$ water in the feed, $12 \mu \mathrm{m})$. 
Citation: Han S, Na S, Li W, Xing W (2016) Development of High Water Selective Sodium Alginate-Silica Hybrid Membranes via Sol-gel Technique for Pervaporation Dehydration of Ethanol. J Membra Sci Technol 6: 165. doi:10.4172/2155-9589.1000165

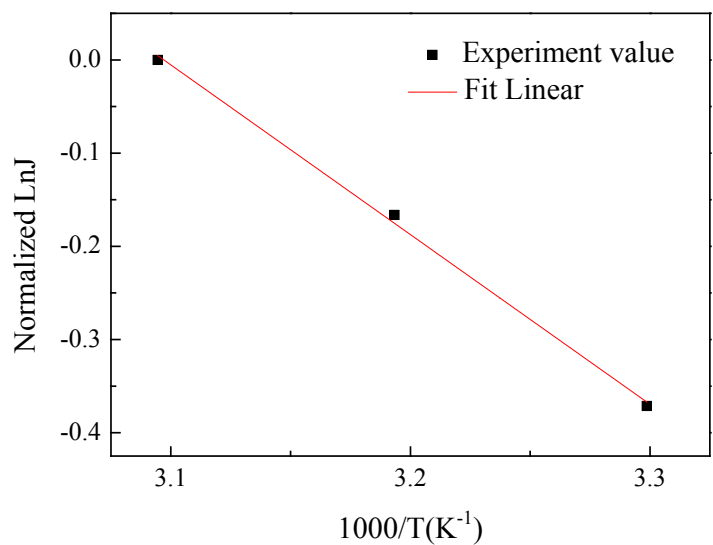

Figure 9: Arrhenius relationship between permeate flux and feed temperature (SA-40 membrane, $10 \mathrm{wt} \%$ water in the feed, $12 \mu \mathrm{m}$ ).

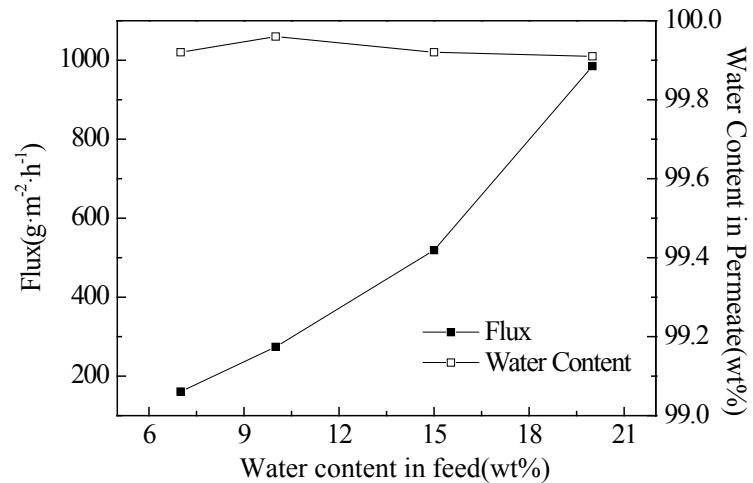

Figure 10: Effect of water content in the feed on pervaporation performance (SA-40 membrane, $\left.50^{\circ} \mathrm{C}, 12 \mu \mathrm{m}\right)$

solution. The thermal stability of hybrid membranes was improved after incorporating TEOS into SA. The tensile strength of SA-40 membrane was enhanced compared to SA membrane. The permeate flux was improved after incorporating TEOS into SA matrix. When the mass ratio of TEOS to SA was $40 \%$, permeate flux reached $274 \mathrm{~g}$ ${ }^{2} \cdot \mathrm{h}^{-1}$ while the water content of permeate side was nearly $100 \mathrm{wt} \%$ with separation factor 17990 .

\section{Acknowledgements}

This work was financially supported by National Natural Science Foundation of China (No. 21576132), National Key Science and Technology Program of China (No. 2013BAE11B01), Jiangsu Province Foundation of China (No. 2013$\mathrm{XCL}-027)$.

\section{References}

1. Chapman PD, Oliveira T, Livingston AG, Li K (2008) Membranes for the dehydration of solvents by pervaporation. J Membr Sci 318: 5-37.

2. Jullok N, Martinez R, Wouters C, Luis P, Sanz MT, et al. (2013) A biologically inspired hydrophobic membrane for application in pervaporation. Langmuir 29: 1510-1516.

3. Saraswathi M, Rao KM, Prabhakar MN, Prasad CV, Subha MCS (2010) Pervaporation studies of sodium alginate (SA)/dextrin blend membranes for separation of water and isopropanol mixture. Desalination 269: 177-183.

4. Gao CY, Zhang MH, Ding JW, Pan FS, Jiang ZY, et al. (2014) Pervaporation dehydration of ethanol by hyaluronic acid/sodium alginate two-active-layer hybrid membranes. Carbohydr Polym 99: 158-165.

5. Dong YQ, Zhang L, Shen JN, Song MY, Chen HL (2006) Preparation of poly(vinyl alcohol)-sodium alginate hollow-fiber hybrid membranes and pervaporation dehydration characterization of aqueous alcohol mixtures. Desalination 193: 202-210.

6. Cao K, Jiang ZY, Zhao J, Zhao CH, Gao CY, et al. (2014) Enhanced water permeation through sodium alginate membranes by incorporating graphene oxides. J Membr Sci 469: 272-283.

7. Amirilargani M, Sadatnia B (2014) Poly(vinyl alcohol)/zeolitic imidazolate frameworks (ZIF-8) mixed matrix membranes for pervaporation dehydration of isopropanol. J Membr Sci 469: 1-10.

8. Adoor SG, Manjeshwar LS, Bhat SD, Aminabhavi TM (2008) Aluminumrich zeolite beta incorporated sodium alginate mixed matrix membranes for pervaporation dehydration and esterification of ethanol and acetic acid. J Membr Sci 318: 233-246.

9. Kulkarni SS, Tambe SM, Kittur AA, Kariduraganavar MY (2006) Modification of tetraethylorthosilicate crosslinked poly(vinyl alcohol) membrane using chitosan and its application to the pervaporation separation of water-isopropano mixtures. J Appl Polym Sci 99: 1380-1389.

10. Premakshia HG, Ramesh K, Kariduraganavar MY, Aminabhavi TM (2015) Modification of crosslinked chitosan membrane using $\mathrm{NaY}$ zeolite for pervaporation separation of water-isopropanol mixtures. Chem Eng Res Des 94: $32-43$

11. Magalad VT, Supale AR, Maradur SP, Gokavi GS, Aminabhavi TM (2010) Preyssler type heteropolyacid-incorporated highly water-selective sodium alginate-based inorganic-organic hybrid membranes for pervaporation dehydration of ethanol. Chem Eng J 159: 75-83.

12. Flynn EJ, Keane DA, Tabari PM, Morris MA (2013) Pervaporation performance enhancement through the incorporation of mesoporous silica spheres into PVA membranes. Sep Purif Technol 118: 73-80.

13. Kariduraganavar MY, Kittur AA, Kulkarni SS, K Ramesh (2004) Development of novel pervaporation membranes for the separation of water-isopropano mixtures using sodium alginate and NaY zeolite. J Membr Sci 238: 165-175.

14. Nigiz FU, Dogan H, Hilmioglu ND (2012) Pervaporation of ethanol/water mixtures using clinoptilolite and $4 \mathrm{~A}$ filled sodium alginate membranes. Desalination 300: 24-31.

15. Hua DU, Ong YK, Wang Y, Yang TX, Chung TS (2014) ZIF-90/P84 mixed matrix membranes for pervaporation dehydration. J Membr Sci 453: 155-167.

16. Rachipudi PS, Kittur AA, Sajjan AM, Kariduraganavar MY (2013) Synthesis and characterization of hybrid membranes using chitosan and 2-(3,4-epoxycyclohexyl) ethyltrimethoxysilane for pervaporation dehydration of isopropanol. J Membr Sci 441: 83-92.

17. Zhao J, Wang F, Pan F, Zhang M, Yang X, et al. (2013) Enhanced pervaporation dehydration performance of ultrathin hybrid membrane by incorporating bioinspired multifunctional modifier and $\mathrm{TiCl}_{4}$ into chitosan. J Membr Sci 446 : 395-404.

18. Ma J, Zhang MH, Lu LY, Yin X, Chen J, et al. (2009) Intensifying esterification reaction between lactic acid and ethanol by pervaporation dehydration using chitosan-TEOS hybrid membranes. Chem Eng J 155: 800-809.

19. Xie ZL, Hoang M, Duong T, Ng D, Dao B, et al. (2011) Sol-gel derived poly(viny alcohol)/maleic acid/silica hybrid membrane for desalination by pervaporation. J Membr Sci 383: 96-103.

20. Mosa J, Durán M, Aparicio M (2010) Epoxy-polystyrene-silica sol-ge membranes with high proton conductivity by combination of sulfonation and tungstophosphoric acid doping. J Membr Sci 361: 135-142.

21. Choudhari SK, Premakshi HG, Kariduraganavar MY (2016) Development of novel alginate-silica hybrid membranes for pervaporation dehydration of isopropanol. Polym Bull 73: 743-762.

22. Kariduraganavar MY, Kulkarni SS, Kittur AA (2005) Pervaporation separation of water-acetic acid mixtures through poly(vinyl alcohol)-silicone based hybrid membranes. J Membr Sci 246: 83-93.

23. Robertson MAF, Mauritz KA (1998) Infrared investigation of the silicon oxide phase in [perfluoro-carboxylate/sulfonate (bilayer)]/[silicon oxide] nanohybrid membranes. J Polym Sci 36: 595-606.

24. Li YF, Jia HP, Pan FS, Jiang ZY, Cheng QL (2012) Enhanced anti-swelling property and dehumidification performance by sodium alginate-poly(vinyl alcohol)/polysulfone composite hollow fiber membranes. J Membr Sci 407 211-220. 
Citation: Han S, Na S, Li W, Xing W (2016) Development of High Water Selective Sodium Alginate-Silica Hybrid Membranes via Sol-gel Technique for Pervaporation Dehydration of Ethanol. J Membra Sci Technol 6: 165. doi:10.4172/2155-9589.1000165

25. Obaid M, Tolba GMK, Barakat NAM (2015) Effective polysulfone-amorphous $\mathrm{SiO} 2 \mathrm{NPs}$ electrospun nanofiber membrane for high flux oil/water separation. Chem Eng J 279: 631-638.

26. Kalyani S, Smitha B, Sridhar S, Krishnaiah A (2008) Pervaporation separation of ethanol-water mixtures through sodium alginate membranes. Desalination 229: 68-81.

27. Sajjan M, Kumar BKJ, Kittur AA, Kariduraganavar MY (2013) Novel approach for the development of pervaporation membranes using sodium alginate and chitosan-wrapped multiwalled carbon nanotubes for the dehydration of isopropanol. J Membr Sci 425: 77-88.
28. Svang-Ariyaskul A, Huang RYM, Douglas PL, Liu LJ (2006) Blended chitosan and polyvinyl alcohol membranes for the pervaporation dehydration of isopropanol. J Membr Sci 280: 815-823.

29. Adoor SG, Rajineekanth V, Nadagouda MN, Chowdoji RC, Dionysiou DD, et al. (2013) Exploration of nanohybrid membranes composed of phosphotungstic acid in sodium alginate for separation of aqueous-organic mixtures by pervaporation. Sep Purif Technol 113: 64-74.

30. Wang J, Zhang WY, Li WX, Xing WH (2015) Preparation and characterization of chitosan-poly (vinyl alcohol)/polyvinylidene fluoride hollow fiber composite membranes for pervaporation dehydration of isopropanol. Korean J Chem Eng 32: $1369-1376$ 